\title{
Triamcinolone acetonide intralesional injection for the treatment of keloid scars: patient selection and perspectives
}

This article was published in the following Dove Press journal:

Clinical, Cosmetic and Investigational Dermatology

\section{Marco Morelli Coppola* \\ Rosa Salzillo* \\ Francesco Segreto \\ Paolo Persichetti}

Department of Plastic, Reconstructive and Aesthetic Surgery, "Campus BioMedico" University of Rome, Rome, Italy

*These authors contributed equally to this work
Correspondence: Marco Morelli Coppola Department of Plastic, Reconstructive and Aesthetic Surgery, "Campus BioMedico" University of Rome, Via Alvaro del Portillo 2I, 00128 Rome, Italy

Tel +3906225418824

Fax +39062254 II 955

Email m.morellicoppola@unicampus.it

\begin{abstract}
Keloids are pathological scars presenting as nodular lesions that extend beyond the area of injury. They do not spontaneously regress, often continuing to grow over time. The abnormal wound-healing process underlying keloid formation results from the lack of control mechanisms self-regulating cell proliferation and tissue repair. Keloids may lead to cosmetic disfigurement and functional impairment and affect the quality of life. Although several treatments were reported in the literature, no universally effective therapy was found to date. The most common approach is intralesional corticosteroid injection alone or in combination with other treatment modalities. Triamcinolone acetonide (TAC) is the most commonly used intralesional corticosteroid. The aim of this article was to review the use of TAC, alone or in combination, in the treatment of keloid scars. The response to corticosteroid injection alone is variable with $50-100 \%$ regression and a recurrence rate of $33 \%$ and $50 \%$ after 1 and 5 years, respectively. Compared to verapamil, TAC showed a faster and more effective response even though with a higher complication rate. TAC combined with verapamil was proved to be effective with statistically significant overall improvements of scars over time and long-term stable results. TAC and 5-fluorouracil (5-FU) intralesional injections were found to achieve comparable outcomes when administered alone, although 5-FU was more frequently associated with side effects. Conversely, the combination of 5-FU and TAC was more effective and showed fewer undesirable effects compared to TAC or 5-FU alone. Several kinds of laser treatments were reported to address keloids; however, laser therapy alone was burdened with a high recurrence rate. Better results were described by combining $\mathrm{CO}_{2}$, pulsed-dye or Nd: YAG lasers with TAC intralesional injections. Further options such as needle-less intraepidermal drug delivery are being explored, but more studies are needed to establish safety, feasibility and effectiveness of this approach.

Keywords: keloids, scars, intralesional corticosteroid injections
\end{abstract}

\section{Introduction}

Keloids are pathological scars presenting as nodular firm lesions that extend beyond the area of injury. They do not spontaneously regress, often continuing to grow over time. ${ }^{1}$ The prevalence is high in the dark phototypes with an estimated incidence of $5-16 \%$ in the Hispanic and African-American populations. ${ }^{1}$ The most frequently affected body areas are chest, shoulders, earlobes and upper back. ${ }^{2}$ Symptoms often include itching and pain. Unlike hypertrophic scars, keloids do not improve over time and commonly recur following surgical excision. ${ }^{3}$ Large lesions may lead to cosmetic disfigurement and functional impairment, thus affecting the quality of life. ${ }^{2}$

The abnormal wound-healing process underlying keloid formation results from the lack of control mechanisms regulating cell proliferation and tissue repair. ${ }^{4}$ 
Histologically, keloids are characterized by haphazardly arranged hyalinized collagen bundles and a tongue-like advancing edge in the papillary dermis. ${ }^{5}$ Despite many clinical, histological and in vitro findings, the pathogenic mechanisms underlying keloid formation have not been fully elucidated. ${ }^{6,7}$ To date, no specific gene has been linked to the development of keloids, and it is likely that different genes contribute to their formation in different families..$^{7-9}$ Excessive matrix accumulation and cell proliferation are distinctive histological features of keloids, resulting from the increased proliferation and lower apoptotic rate of fibroblasts. ${ }^{7,10,11}$ The change in the normal balance between extracellular matrix (ECM) deposition and degradation seen during wound healing, especially along the remodeling phase, may play a role in keloid formation. Increased local levels of PAI-1 and low levels of urokinase have been reported in keloid fibroblasts, likely leading to reduced collagen degradation. ${ }^{7,12,13}$ Several other pathogenic theories have also been postulated, including genetic immune dysfunction, mechanical tension, increased hyaluronic acid production, sebum reaction, tissue hypoxia and abnormal epithelialmesenchymal interaction. ${ }^{7,8,12-15}$ Elevated levels of cytokines, such as tumor necrosis factor (TNF), interleukin (IL)-6 and IL-13, and growth factors, such as vascular endothelial growth factor (VEGF) and transforming growth factor beta (TGF- $\beta$ ), were proved to be involved in keloid scar formation and proliferation. ${ }^{716}$ TGF- $\beta$ family was associated with enhanced collagen synthesis in keloid fibroblasts. TGF- $\beta 1$ treatment was shown to stimulate the production of collagen in keloid fibroblasts but not in normal skin fibroblasts. ${ }^{16,17}$ The role of TGF- $\beta 1$ was further confirmed by the observation that anti-TGF- $\beta 1$ antibody suppressed collagen synthesis of keloid fibroblasts. ${ }^{16,17}$ Moreover, TGF- $\beta 2$ treatment enhanced collagen production of xenograft derived from human keloid specimens in athymic rats. ${ }^{16,18}$ On the other hand, TGF- $\beta 2$ antibody inhibited collagen generation in a xenograft model, suggesting that it could act as a potential antiscarring agent. ${ }^{18} \mathrm{IL}-13$ induced a faster increase in collagen production by keloid fibroblasts compared to normal ones. ${ }^{16,19}$ VEGF is one of the most important growth factors involved in angiogenesis, and it was previously implicated as crucial to both normal and pathological wound healing. ${ }^{6,7}$ In vivo and in vitro studies showed that VEGF was overexpressed in keloid tissue and may play a potential role in its formation. ${ }^{6,711}$ VEGF induces angiogenesis both directly, by acting as a mitogen for endothelial cells, and indirectly, by increasing vascular hyperpermeability and promoting the extravascular deposition of fibrin matrix. It is also paramount in the modulation of ECM proteolysis, an essential component of the angiogenic process. ${ }^{7,20,21}$

Several strategies were suggested for keloid therapy, but, to date, no universally effective treatment was found. ${ }^{22}$ Current therapeutic approaches fall into three broad categories: alteration of the inflammatory response; modification of collagen metabolism; surgical and physical manipulation of the keloid scar. ${ }^{7}$ Therapeutic approaches include surgical excision, intralesional injection of steroids, verapamil, 5-fluorouracil (5-FU), cryotherapy, laser therapy (fractionated $\mathrm{CO}_{2}$ laser, Nd:YAG laser, pulsed-dye laser), silicone sheet dressings, irradiation, retinoids, tacrolimus, imiquimod and combination therapy.

Since keloids are notoriously characterized by a high recurrence rate after surgical excision, nonsurgical approaches are recommended for primary treatment., ${ }^{3,16}$ The most common approach is intralesional corticosteroid injection alone or in combination with other treatment modalities. Triamcinolone acetonide (TAC) is the most commonly used intralesional corticosteroid.

The aim of this review was to investigate and discuss the efficacy of TAC intralesional injection in the treatment of keloids.

\section{Intralesional injection of TAC}

The International Advisory Panel on Scar Management recommended the use of intralesional steroid injections for the treatment of keloids and hypertrophic scars. ${ }^{3}$ Corticosteroids were proved to induce keloid regression through many different mechanisms. First, they suppress inflammation by inhibiting leukocyte and monocyte migration and phagocytosis. ${ }^{23}$ Second, they are powerful vasoconstrictors, thus reducing the delivery of oxygen and nutrients to the wound bed. ${ }^{23}$ Third, they have an antimitotic effect that inhibits keratinocytes and fibroblasts, slowing reepithelialization and new collagen formation. Furthermore, they may reduce plasma protease inhibitors, thus allowing collagenase to degrade collagen. TAC also induces a significant plunge in alpha-1-antitrypsin and alpha-2-macroglobulin levels, which tend to be greater in keloidal tissue and are natural inhibitors of collagenase in human skin. ${ }^{24}$ Corticosteroids affect fibroblast proliferation and production capabilities and are responsible for their degeneration. Moreover, decreased levels of TGF- $\beta$, insulin-like growth factor-1 (IGF-1) and hydroxyproline were found in scar tissues treated with methylprednisolone. ${ }^{24,25}$ It was shown that dexamethasone induced keloid regression via interaction with glucocorticoid receptors and 
suppressed endogenous VEGF expression and fibroblast proliferation. ${ }^{6,23}$

Many corticosteroids are available for the treatment of keloids, but the most commonly used is TAC. Clinically, the response to corticosteroid injection alone was variable with $50-100 \%$ regression and a recurrence rate of $33 \%$ and $50 \%$ after 1 and 5 years, respectively. ${ }^{3,26}$ Five-year recurrence rates for surgical excision followed by TAC administration were reported to be between $8 \%$ and $50 \%{ }^{3}$

There were considerable differences among practitioners in the dose, frequency and duration of treatment (Table 1). Rahban and Garner ${ }^{27}$ proposed performing two to three injections of Kenalog (Bristol-Myers Squibb, Princeton, NJ, USA), at a dose of $10 \mathrm{mg} / \mathrm{mL}$, approximately 4-8 weeks apart. Darzi et $\mathrm{al}^{28}$ adjusted the dosage of TAC administered to patients depending on the keloid scar surface area: patients with a keloid scar surface area of $1-2 \mathrm{~cm}^{2}$ received a total dose of 20-40 mg of TAC $0.1 \%$, those with $2-6 \mathrm{~cm}^{2}$ received $60-80 \mathrm{mg}$ and those with $6-12 \mathrm{~cm}^{2}$ received $80-120 \mathrm{mg}$. At 10 -year follow-up, $71 \%$ of the treated keloid scars evidenced full flattening and $29 \%$ had partial flattening. Symptom relief was seen in $71 \%$ of the treated keloid scars, although this outcome measure was not defined. Four injections were given until the total dose was reached. Robles et $\mathrm{al}^{9}$ recommended the use of TAC (Kenalog) at a concentration ranging from 10 to $40 \mathrm{mg} / \mathrm{mL}$, depending on the size and location of the lesion. For lesions on the trunk or extremities, therapy was usually initiated at $40 \mathrm{mg} / \mathrm{mL}$ and then titrated accordingly at subsequent visits.

Acosta et $\mathrm{al}^{29}$ conducted a prospective clinical trial with patients aged 1-14 years. They studied keloid treatment with intralesional TAC to determine its effectiveness as a single therapy and to establish whether the affected area, the etiology of the lesion and the duration of a scar were the outcome predicting factors. Before treatment, keloid volume was calculated using soft tissue ultrasound, which was repeated after 3 months to compare volume differences attributable to therapy. If a palpable or visible lesion persisted, keloids were reinjected each month with the same dose until no volume change was perceived between sessions. Three months after the last procedure, a further ultrasound was performed to assess for any recurrence. Results showed an $82.7 \%$ reduction in size between the first and last treatments $(p<0.001)$. The median number of injections required per keloid was two (range one to five). The median dose for each session was $16 \mathrm{mg}$ of TAC (range 4-40 mg), and the median dose to complete the treatment was $32 \mathrm{mg}$ (range $4-80 \mathrm{mg}$ ). Their findings indicated a trend toward better response in those lesions caused by a trauma or a surgical scar rather than in those resulting from varicella or vaccination, although the difference was not statistically significant. Furthermore, keloids on the earlobe had a worse response than those on the arm, chest or other locations, although the difference was not statistically significant. The duration of the keloid before starting treatment had no effect on the treatment result. The authors therefore concluded that there was no relationship among clinical response and the lesion location, etiology and age of the keloid.

Despite its benefits, intralesional steroid injections may cause several adverse side effects, both local, such as telangiectasias, skin and subcutaneous fat atrophy, pigmentary changes (hypopigmentation and hyperpigmentation), skin

Table I Dose of TAC used by different authors when using TAC in monotherapy and in combination therapy

\begin{tabular}{|c|c|c|c|c|}
\hline Study & $\begin{array}{l}\text { TAC dose and/or } \\
\text { concentration }\end{array}$ & $\begin{array}{l}\text { Associated } \\
\text { treatment }\end{array}$ & $\begin{array}{l}\text { Number of } \\
\text { injections }\end{array}$ & $\begin{array}{l}\text { Interval between } \\
\text { sessions (weeks) }\end{array}$ \\
\hline Rahban and Garner ${ }^{26}$ & $10 \mathrm{mg} / \mathrm{mL}$ & - & $2-3$ & $4-8$ \\
\hline Darzi et $\mathrm{al}^{27}$ & $10-20 \mathrm{mg} / \mathrm{cm}^{2}$ & - & 4 & - \\
\hline Robles et al $^{9}$ & $10-40 \mathrm{mg} / \mathrm{mL}$ & - & Multiple & 4 \\
\hline Acosta et $\mathrm{al}^{28}$ & $4-40 \mathrm{mg} / \mathrm{mL}$ & - & $\mathrm{I}-5$ & 4 \\
\hline Ahuja and Chatterjee ${ }^{37}$ & $40 \mathrm{mg} / \mathrm{mL}$ & - & Maximum 8 & 3 \\
\hline Danielsen et $\mathrm{al}^{38}$ & I mg/cm (maximum 5 mg) & $\begin{array}{l}\text { Surgical excision } \\
\text { (before TAC injection) }\end{array}$ & 4 & 4 \\
\hline Kant et $\mathrm{al}^{39}$ & $2-4 \mathrm{mg}$ of TAC $40 \mathrm{mg} / \mathrm{mL}$ & $\begin{array}{l}0.05-0.1 \mathrm{~mL} \text { of } \\
\text { verapamil } 2.5 \mathrm{mg} / \mathrm{mL}\end{array}$ & 3 & $\begin{array}{l}\text { Second injection after I week, } \\
\text { third injection } 3 \text { weeks later }\end{array}$ \\
\hline Saha and Mukhopadhyay ${ }^{43}$ & $40 \mathrm{mg} / \mathrm{mL}$ & - & Maximum 6 & I \\
\hline Fitzpatrick ${ }^{45}$ & $\mathrm{I} \mathrm{mg}$ & 5-FU $45 \mathrm{mg}$ & $5-10$ & - \\
\hline Khan et $\mathrm{al}^{46}$ & $4 \mathrm{mg}$ & 5-FU $45 \mathrm{mg}$ & 8 & I \\
\hline Tan et $\mathrm{al}^{71}$ & $40 \mathrm{mg} / \mathrm{mL}$ & - & - & 4 \\
\hline Kassab and El Kharbotly ${ }^{63}$ & $40 \mathrm{mg} / \mathrm{mL}$ & $980 \mathrm{~nm}$ diode laser & $2-5$ & - \\
\hline Payapvipapong et $\mathrm{al}^{77}$ & $10 \mathrm{mg} / \mathrm{mL}$ & - & 3 & 4 \\
\hline
\end{tabular}

Abbreviations: 5-FU, 5-fluorouracil; TAC, triamcinolone acetonide. 
necrosis and ulcerations, and systemic effects, such as Cushing's syndrome. The risk of local complications is greater when inadvertent injection of surrounding normal tissue occurs. ${ }^{23}$ Cushing's syndrome with adrenal insufficiency associated with intradermal corticosteroid injection is a rare but possible complication, usually reported in children, although a few cases were described in adults as well. ${ }^{30-32}$ Such major adverse effect is associated with a high cumulative dose of TAC in adults, whereas in children it has been observed even after a single treatment with $40 \mathrm{mg}$ of triamcinolone, thus care must be taken when administering TAC in children and patients with multiple or very large lesions. ${ }^{33}$ Therefore, the occurrence of symptoms such as weight gain, striae rubrae, depression, moon face and amenorrhea in the course of treatment must not be underestimated but must be further investigated.

Intradermal corticosteroid injection was associated with significant injection pain, often requiring the administration of local anesthetics. Furthermore, the injection itself may be physically challenging due to the density of the lesion: the physician must be able to comfortably generate enough injection pressure to overcome this resistance. ${ }^{34}$ Vo et $\mathrm{al}^{35}$ investigated the effects of various syringe and needle combinations on the injection force to determine the most ergonomic combination. They found that the $1 \mathrm{~mL}$ polycarbonate syringe with a $25 \mathrm{G}, 16 \mathrm{~mm}$ needle was the combination requiring the lowest injection force; thus, it was the most ergonomic combination for injecting into keloids.

\section{TAC intralesional injection compared and combined with other treatment modalities \\ Triamcinolone and verapamil}

Verapamil is a calcium antagonist, which is commonly used for treating hypertension and cardiac arrhythmias. It is also able to depolymerize actin filaments, thus modifying fibroblast morphology from a bipolar to a spheroidal shape, consequently increasing the synthesis of procollagenase in the ECM, leading therefore to an increase in collagen degradation. ${ }^{36,37}$

Ahuja and Chatterjee ${ }^{38}$ compared triamcinolone $(40 \mathrm{mg}$ / $\mathrm{mL})$ and verapamil $(2.5 \mathrm{mg} / \mathrm{mL})$ intralesional injections in a non-inferiority blinded clinical trial. Injections were performed every 3 weeks until complete flattening of the scar, for a maximum of eight sessions. Scar pliability, vascularity, height and pigmentation were evaluated by Vancouver Scar Scale (VSS) score. Mean zero VSS scores were achieved with both treatments with respect to scar height, vascularity and pliability, but the response to TAC was faster and more effective, although with a higher complication rate (skin atrophy and telangiectasias). Conversely, no adverse effects were reported with verapamil, except for the injection-related pain requiring analgesia. The study, limited by the 6-month follow-up, was unable to provide data on the tendency of the scar toward hypertrophy in the longer term.

TAC was shown to be more effective than verapamil in preventing keloid recurrence after surgical excision, as found by Danielsen et al. ${ }^{39}$ The peculiarity of the study was the paired split-scar design, each patient being their own control: 14 patients with keloid scars were enrolled; after surgical excision, one-half of the suture line was randomly allocated to receive triamcinolone $2 \mathrm{mg} / \mathrm{cm}$ (maximum total dose $10 \mathrm{mg}$ ), whereas the other half received verapamil hydrochloride $0.5 \mathrm{mg} / \mathrm{cm}$ (maximum total dose $2.5 \mathrm{mg}$ ). Intradermal injection of both drugs was performed immediately postoperatively and every 4 weeks for 3 months. Since atrophy occurred in the steroid-treated half of the scar in four patients (who were excluded from the trial), TAC dose was halved to $1 \mathrm{mg} / \mathrm{cm}$ (maximum total dose $5 \mathrm{mg}$ ) for new and ongoing subjects. At 12-month follow-up, a significantly higher overall risk of recurrence was found with verapamil.

From a biological standpoint, since triamcinolone acts by decreasing proteinase inhibitors and verapamil acts by increasing procollagenase secretion, the effect resulting from the association of both drugs is to increase collagenase levels, thus achieving collagen degradation within the scar. ${ }^{37}$ Such a potential synergistic effect was investigated by Kant et $\mathrm{al}^{40}$ in a retrospective study conducted between 2012 and 2015 on 58 patients treated with a $1: 1$ mixture of triamcinolone $40 \mathrm{mg} / \mathrm{mL}$ and verapamil $2.5 \mathrm{mg} / \mathrm{mL}$. The treatment schedule consisted of a first injection, then repeated 1 and 4 weeks later. Improvements in scar surface area, pliability, relief, pain and itchiness were detected in the keloids' group (27 patients). Patient and Observer Scar Assessment Scale (POSAS) scores, with evaluation at baseline and five follow-up moments (1-3, 3-4, 4-6, 6-12 and $>12$ months), showed that triamcinolone combined with verapamil was effective at a relatively early stage with statistically significant overall improvements of scars over time.

Hence, verapamil, compared to TAC, is associated with a lower complication rate but higher risk of recurrence. Combined therapy is effective and offers long-term stable results.

\section{Triamcinolone and 5-FU}

5-FU is a pyrimidine analog with antimetabolite activity, which is able to block collagen synthesis in vitro by reducing fibroblast activity and to inhibit the TGF- $\beta$-induced 
expression of the type I collagen gene in human fibroblasts. ${ }^{41-43}$ Other than in chemotherapy for some kinds of metastatic cancers, it is widely used in the treatment of hypertrophic and keloid scars.

Several studies compared the efficacy of TAC and 5-FU. Saha and Mukhopadhyay ${ }^{44}$ conducted a controlled trial over a period of 2.5 years on 44 patients, randomized into two study groups: patients of the first group were treated with intralesional 5-FU $(50 \mathrm{mg} / \mathrm{mL})$; those of the second group with TAC $(40 \mathrm{mg} / \mathrm{mL})$. Both groups received injections at weekly intervals for a maximum of six sessions. Even for bigger lesions, the maximum delivered dose never exceeded $2 \mathrm{~mL}$. The reduction in keloid volume (flattening, decrease in length and width) and decrease in itching appeared to be comparable in both groups as well as the recurrence rate within 6 months from the last treatment. However, side effect rates during and after treatment were significantly higher in patients treated with 5-FU: most of them experienced pain ( $95 \%$ vs $4 \%$; $p<0.05$ ), hyperpigmentation ( $90 \%$ vs $12.5 \%$, $p=0.000)$ and superficial ulceration $(65 \%)$ at the injection site. Specifically, no ulceration was observed in any of the patients of the other group $(p=0.000)$. Although no systemic hematologic side effect was reported with 5-FU, triamcinolone was better tolerated.

On the other hand, Sadeghinia and Sadeghinia, ${ }^{45}$ in a double-blind clinical trial comparing intralesional injection of triamcinolone and 5-FU administration by tattooing technique, obtained better results with 5-FU. Statistical analysis showed better results in the 5-FU group in terms of decrease in height and surface of the lesions, erythema, induration and pruritus reduction; observers' evaluation and patients' self-assessment were significantly better for the same group. At week 44, no side effects were noted in either of the two groups. The positive outcome could be related to the longer intervals between each administration session (one every 4 weeks apart) and to the peculiar method of intralesional delivery of the drug: double dripping of $5-\mathrm{FU}(50 \mathrm{mg} / \mathrm{mL})$ after multiple drilling of the scar by $27 \mathrm{G}$ needle and subsequent occlusion of the keloid.

Even with standard intralesional delivery of the drug, the addition of triamcinolone to 5-FU may produce more effective results and reduce the injection-related pain, as reported for the first time by Fitzpatrick ${ }^{46}$ in his 9 -year experience. His formula was made by adding $1 \mathrm{mg}$ of TAC to $45 \mathrm{mg}$ of 5-FU. Injections were repeated for a mean of 5-10 times.

Khan et $\mathrm{al}^{47}$ compared the use of intralesional TAC alone and its combination with 5-FU for the treatment of keloidal and hypertrophic scars. The combination used, $45 \mathrm{mg}$ of
5 -FU $(0.9 \mathrm{~mL}$ of $250 \mathrm{mg} / 5 \mathrm{~mL})$ and $4 \mathrm{mg}$ of TAC $(0.1 \mathrm{~mL}$ of $40 \mathrm{mg} / 1 \mathrm{~mL}$ ), was administered weekly for 8 weeks. This combination had already been reported as effective. ${ }^{48}$ The study found that the combination therapy was superior to TAC alone in reducing the initial height of the scar, also offering a faster response, with fewer undesirable effects, such as skin atrophy and telangiectasias. Similar findings were reported in other studies. ${ }^{49-51}$

It is important to understand that a dose of $10-40 \mathrm{mg} / \mathrm{mL}$ of TAC is usually required to have any effect in keloid or hypertrophic scar reduction. The small amount of TAC used in combination with 5-FU is not therapeutic, but it might play an important role in reducing 5-FU-induced inflammation. Side effects such as erythema, hyperpigmentation and ulceration are common when pure 5-FU is used. A small concentration of TAC may reduce the risk of such local side effects. ${ }^{47}$

\section{Triamcinolone and laser therapy}

Different kinds of laser treatments were described to address keloids. Laser therapies for keloids fall into two categories: ablative and non-ablative. Ablative lasers, such as the $2940 \mathrm{~nm}$ erbium:YAG laser and the $10600 \mathrm{~nm} \mathrm{CO}_{2}$ laser, emit energy absorbed by water in skin resulting in local tissue destruction. Non-ablative lasers target skin chromophores, such as hemoglobin or melanin, according to the principle of selective photothermolysis. The 585 or $595 \mathrm{~nm}$ pulsed-dye lasers, the $980 \mathrm{~nm}$ diode laser and the $1064 \mathrm{~nm} \mathrm{Nd:YAG} \mathrm{laser}$ cause selective damage to blood vessels that supply the scar. ${ }^{52}$ The heat energy produced by lasers causes collagen denaturation, dissociating disulfide bonds and realigning collagen fibers. ${ }^{53-55}$ Therefore, it is plausible that non-ablative lasers may interact directly with and affect the biological function of keloidal fibroblasts. However, laser therapy alone (pulsed dye, $\left.\mathrm{CO}_{2}, \mathrm{Nd}: \mathrm{YAG}\right)$ is burdened with a high recurrence rate at 6-24 months. ${ }^{56-60}$ For $\mathrm{CO}_{2}$ laser, better results were reported in association with $2 \mathrm{~mL}$ of triamcinolone $40 \mathrm{mg} / \mathrm{mL}$ injection. ${ }^{61}$ In a clinical study on 17 patients, whose keloids had been previously treated by Nd:YAG laser, complete resolution and full flattening in seven patients were achieved only by intralesional TAC, following the laser procedures. ${ }^{62}$ In a retrospective study, combined therapy of $300 \mu \mathrm{s} 1064 \mathrm{~nm}$ $\mathrm{Nd}$ :YAG laser plus intralesional triamcinolone proved more effective than corticosteroid alone in reducing thickness and erythema of the keloid scars. No hyperpigmentation nor hypopigmentation was detected, even in Fitzpatrick skin types IV to VI. ${ }^{63}$

Kassab and El Kharbotly ${ }^{64}$ described successful treatment of ear lobule keloids with $980 \mathrm{~nm}$ diode laser (single mode, 
4-second duration, $5 \mathrm{~W}$ power, $20 \mathrm{~J} / \mathrm{cm}^{2}$ energy fluence). In each laser treatment session, five to nine pulses were delivered, depending on the lesion size and darkness degree. Each laser session was followed by intralesional injection of $1 \mathrm{~mL}$ of $40 \mathrm{mg} / \mathrm{mL}$ TAC. An effective response, or rather a decrease in the keloid size of $75 \%$ or more, was achieved in 12 out of 16 lesions. The number of sessions needed to achieve the best result ranged from two to five. Skin erythema was observed immediately in all patients, whereas persistent minimal hyperpigmentation was recorded in four lesions.

Recently, Kraeva et $\mathrm{al}^{1}$ suggested an alternative method of administration of the corticosteroid: laser-assisted drug delivery of topical TAC, following each session of $\mathrm{CO}_{2}$ laser, was successfully employed for a keloid on the posterior scalp in an African-American man. According to the authors, the laser enhanced the drug delivery to the dermis, avoiding painful injections; on the other hand, the steroid decreased the risk of post-inflammatory hyperpigmentation, following the laser procedure.

More advanced possibilities of needle-less intraepidermal drug delivery are being explored: Singhal et al ${ }^{65}$ created polymeric microparticles containing TAC, which were prepared using a freeze fracture technique employing cryomilling. These microparticles can be deposited in cutaneous micropores following ablation with fractional erbium:YAG laser. This technique could provide high-dose intraepidermal drug reservoir systems, resulting in a sustained and localized action, with minimal transdermal permeation. Further preclinical and clinical studies are needed to establish safety, feasibility and effectiveness of this approach.

\section{Triamcinolone and silicone gel sheet}

Topical silicone gel sheet was first reported as an effective treatment for burn scars by Perkins et al. ${ }^{66}$ Gold $^{67}$ showed that 12 weeks of treatment with silicone dressing was effective in improving hypertrophic scars and keloids, recommending it as the optimal duration of treatment. The mechanisms of silicone gel sheet on keloids are only partially known. It has been shown that occlusion decreases IL-l $\alpha$ mRNA, which results in a reduction in pro-inflammatory IL- $1 \alpha$ and IL- 6 and subsequent human fibroblast synthesis and activation. ${ }^{68,69}$

Many authors, such as Fulton ${ }^{70}$ and Katz, ${ }^{71}$ investigated the efficacy of silicone gel sheeting in the treatment of keloids, reporting a high success rate, although lacking a comparison to other treatment modalities.

Tan et $\mathrm{al}^{72}$ compared the effectiveness of silicone gel sheet and intralesional TAC injections. They reported that only two of the 17 lesions treated with silicone gel sheet showed a reduction in size greater than $50 \%$. This result, however, was not statistically significant $(p<0.05)$ when compared to the untreated control lesions. Conversely, 16 of the 17 lesions treated with intralesional TAC injections at a concentration of $40 \mathrm{mg} / \mathrm{mL}$ and 4 weeks of time interval showed a significant reduction in size, and this result was statistically significant $(p<0,05)$ when compared to the untreated lesions.

Only three articles comparing silicone gel sheet and TAC intralesional injections for the treatment of keloids were found in the literature. ${ }^{72-74}$ Further comparative studies with a higher population for each group would be useful for a better understanding.

\section{Excision and radiation}

The combination of surgical excision plus postoperative irradiation is another option for treating keloids. The recurrence and efficacy rates reported in the literature vary significantly. The recurrence rate ranges from $10 \%$ to $100 \%{ }^{3}$

Yamawaki et $\mathrm{al}^{75}$ showed their experience with the combination of surgical excision and radiation therapy. They treated 91 keloids with extralesional excision and irradiation 72 hours after the operation. The total dose was $20 \mathrm{~Gy}$ delivered in five fractions of 4 Gy per every other day, except for ear keloids which were given a total dose of 16 Gy in four fractions. During the follow-up period, they detected signs of recurrence in 46 of 91 keloids that were treated with intralesional TAC injections. At the end of follow-up time, 5 years after the surgical excision and radiation therapy, 81 of 91 keloids showed excellent or good results.

Kuo et $\mathrm{al}^{76}$ showed that irradiation and intralesional corticosteroid injections can suppress the synthesis of type I collagen and fibronectin by keloid fibroblasts. However, the underlying molecular mechanisms remain largely unknown. Irradiation is likely to damage the majority of keloid cells but may not be strong enough to completely remove all cells. This might explain the high recurrence rate of this treatment modality and the need to administer intralesional TAC injections to inhibit re-propagation of the keloid from certain cell types that are resistant to irradiation. One of the major concerns about radiation therapy is its potential carcinogenic effect that depends on the dose, organ and age. The authors, in fact, in their protocol, administered a dose not greater than 20 Gy and did not irradiate patients aged $<10$ years.

\section{Triamcinolone and bleomycin}

Bleomycin is a water-soluble glycopeptide antibiotic with anticarcinogenic, antibacterial and antiviral effects. 
Bodokh and Brun ${ }^{77}$ first used bleomycin to treat keloids, showing complete remission in $47 \%$ of cases. Further studies demonstrated the efficacy of intralesional bleomycin injections. ${ }^{78-80}$

Payapvipapong et $\mathrm{al}^{78}$ compared the efficacy of intralesional bleomycin injections $(1 \mathrm{IU} / \mathrm{mL})$ to intralesional TAC $(10 \mathrm{mg} / \mathrm{mL})$ injections; 26 patients were included in the study and divided into two groups, each treated either with bleomycin or with TAC injections once every 4 weeks for three consecutive sessions. They assessed results with both objective measures, such as photography and ultrasonography, and subjective measures, such as POSAS and self-rated patient satisfaction score. No difference between the two groups was reported. The authors reported, however, a high rate of hyperpigmentation (71.4\%), partially due to the population being Fitzpatrick type III-IV. For this reason, TAC is recommended over bleomycin in darker skin populations.

\section{Triamcinolone and pressure therapy}

Pressure therapy was introduced in the 1970s when clinicians noted that pressure stockings applied on lower extremity wounds reduced erythema and scar thickness. ${ }^{81}$ Pressure causes localized hypoxia, decreased intercollagenous cohesion, increased collagenase activity and, hence, fibroblast degeneration. ${ }^{3,82}$ Furthermore, it induces reorientation of the scar collagen fibers (that become parallel to skin surface), increases hyaluronic acid levels and decreases chondroitin sulfate levels, promoting flattening of the initially elevated scar tissue and reducing the recurrence rates. ${ }^{14,83-84}$

The minimum effective pressure to cause collagen fragmentation and fibroblast degradation should be at least $24 \mathrm{mmHg}$ to exceed the capillary pressure, but it should remain under $30 \mathrm{mmHg}$ to avoid a decrease in peripheral blood circulation resulting in tissue necrosis. ${ }^{83,85}$ Although the precise mechanism of compression is not fully understood, success rates of $60-85 \%$ were reported from pressure therapy in monotherapy. These rates increased to $90-100 \%$ when pressure therapy was applied in combination with surgical excision of keloids. ${ }^{86}$

Carvalhaes et $\mathrm{al}^{87}$ developed a device similar to an earring to treat auricular keloids with pressure therapy. They treated 81 earlobe keloids with TAC intralesional injections $(20-40 \mathrm{mg} / \mathrm{mL})$ once a month for 3 months. They subsequently performed surgical excision and perioperative infiltration in the 4 th month, followed by two more TAC injections in the following 2 months. After surgical excision, patients applied pressure earrings on the scar 18 hours/day for 4 months. The earrings exerted a pressure of $30 \mathrm{mmHg}$ but were well tolerated by patients. Results showed very good outcomes with only three recurrences in less than a year. The authors therefore suggested pressure therapy as a very effective method to improve the quality of the scar.

Bran et $a^{88}$ developed a similar auricular compression device in 2012 made of two transparent subunits fabricated with acrylate and custom made for every patient. They treated seven auricular keloids with surgical excision and TAC intralesional injection followed by the application of the auricular compression device overnight for at least five nights per week until the scar level matched the level of the surrounding healthy skin. They observed no recurrence during a mean 24-month follow-up time. This device had the advantage of controlling adequately intralesional blood circulation during treatment, thanks to its transparency.

Pressure is more difficult to attain in other body parts, but it should be considered as a good adjuvant therapy for auricular keloids, because it is noninvasive and well tolerated by patients.

\section{Conclusion}

TAC intralesional injection is the most widely used treatment for keloid scars, primarily or after surgical excision, alone or in combination with 5-FU, verapamil and bleomycin. It is considered the gold standard in nonsurgical management of hypertrophic and keloid scars. It was proved to be effective in reducing keloid scar dimensions, alleviating symptoms such as itching and pain and preventing recurrence. Alone, it is more effective than verapamil and better tolerated than 5-FU and bleomycin. However, local complications such as delayed wound healing, hypopigmentation, dermal atrophy, telangiectasias, widening of the scar and systemic adverse effects such as Cushing's syndrome may occur. Care must be taken when administering triamcinolone in children and patients with multiple or very large lesions: in such cases, intralesional steroid injection may be unviable since the pain of injection is considerable and large doses of corticosteroids are needed.

Combined treatments are usually associated with better outcomes and higher patients' satisfaction. Association of triamcinolone and verapamil was proved to be effective in ensuring significant overall improvements of the scars over time and long-term stable results. Combined administration of triamcinolone and 5-FU may reduce injection-site 5-FU-related undesirable effects, such as pain, erythema and superficial ulceration.

Triamcinolone reduces keloid recurrence after surgical excision, followed or not by radiation therapy or 
laser (pulsed dye, $\mathrm{Nd}$ : $\mathrm{YAG}, \mathrm{CO}_{2}$ ) ablation. It can also prevent post-inflammatory hyperpigmentation after laser treatments.

In the treatment of earlobe keloids, pressure devices may play an important role, in combination with triamcinolone intralesional injection.

New mechanisms of intraepidermal needle-less delivery of the drug are being explored: they might improve the efficacy and limit the risk of adverse reactions, in particular those related to systemic exposure. However, further preclinical and clinical trials are needed to establish safety and efficacy of this kind of administration.

\section{Disclosure}

The authors report no conflicts of interest in this work.

\section{References}

1. Kraeva E, Ho D, Jagdeo J. Successful treatment of keloid with fractionated carbon dioxide $\left(\mathrm{CO}_{2}\right)$ laser and laser-assisted drug delivery for triamcinolone acetonide ointment in an African-American man. $J$ Drugs Dermatol. 2017;16(9):925-927.

2. Robles DT, Berg D. Abnormal wound healing: keloids. Clin Dermatol. 2007;25(1):26-32.

3. Mustoe TA, Cooter RD, Gold MH, et al; International Advisory Panel on Scar Management. International clinical recommendations on scar management. Plast Reconstr Surg. 2002;110(2):560-571.

4. Gao Z, Wang Z, Shi Y, et al. Modulation of collagen synthesis in keloid fibroblasts by silencing Smad2 with siRNA. Plast Reconstr Surg. 2006;118(6):1328-1337.

5. Jumper N, Paus R, Bayat A. Functional histopathology of keloid disease. Histol Histopathol. 2015;30(9):1033-1057.

6. Wu WS, Wang FS, Yang KD, Huang CC, Kuo YR. Dexamethasone induction of keloid regression through effective suppression of VEGF expression and keloid fibroblast proliferation. J Invest Dermatol. 2006;126(6):1264-1271.

7. Salem A, Assaf M, Helmy A, et al. Role of vascular endothelial growth factor in keloids: a clinicopathologic study. Int J Dermatol. 2009;48(10):1071-1077.

8. Bayat A, Arscott G, Ollier WE, Ferguson MW, McGrouther DA. "Aggressive keloid": a severe variant of familial keloid scarring. $J R$ Soc Med. 2003;96(11):554-555.

9. Robles DT, Moore E, Draznin M, Berg D. Keloids: pathophysiology and management. Dermatol Online J. 2007;13(3):9.

10. Saed GM, Ladin D, Olson J, Han X, Hou Z, Fivenson D. Analysis of p53 gene mutations in keloids using polymerase chain reaction-based single-strand conformational polymorphism and DNA sequencing. Arch Dermatol. 1998;134(8):963-967.

11. Tanaka A, Hatoko M, Tada H, Iioka H, Niitsuma K, Miyagawa S. Expression of p53 family in scars. J Dermatol Sci. 2004;34(1):17-24.

12. Shaffer JJ, Taylor SC, Cook-Bolden F. Keloidal scars: a review with a critical look at therapeutic options. J Am Acad Dermatol. 2002;46(2 suppl Understanding):S63-S97.

13. Butler PD, Longaker MT, Yang GP. Current progress in keloid research and treatment. J Am Coll Surg. 2008;206(4):731-741.

14. Al-Attar A, Mess S, Thomassen JM, Kauffman CL, Davison SP. Keloid pathogenesis and treatment. Plast Reconstr Surg. 2006;117(1):286-300.

15. Akaishi S, Ogawa R, Hyakusoku H. Keloid and hypertrophic scar: neurogenic inflammation hypotheses. Med Hypotheses. 2008;71(1):32-38.

16. Wong T-S, Li JZ-H, Chen S, Chan JY-W, Gao W. The efficacy of triamcinolone acetonide in keloid treatment: a systematic review and meta-analysis. Front Med (Lausanne). 2016;3:71.
17. Younai S, Nichter LS, Wellisz T, Reinisch J, Nimni ME, Tuan TL. Modulation of collagen synthesis by transforming growth factor-beta in keloid and hypertrophic scar fibroblasts. Ann Plast Surg. 1994;33(2):148-151.

18. Wang X, Smith P, Pu LL, Kim YJ, Ko F, Robson MC. Exogenous transforming growth factor beta(2) modulates collagen I and collagen III synthesis in proliferative scar xenografts in nude rats. J Surg Res. 1999;87(2):194-200.

19. Oriente A, Fedarko NS, Pacocha SE, Huang SK, Lichtenstein LM, Essayan DM. Interleukin-13 modulates collagen homeostasis in human skin and keloid fibroblasts. J Pharmacol Exp Ther. 2000;292(3):988-994.

20. Chau CH, Clavijo CA, Deng HT, et al. Etk/Bmx mediates expression of stress-induced adaptive genes VEGF, PAI-1, and iNOS via multiple signaling cascades in different cell systems. Am J Physiol Cell Physiol. 2005;289(2):C444-C454.

21. Giugliano G, Pasquali D, Notaro A, et al. Verapamil inhibits interleukin-6 and vascular endothelial growth factor production in primary cultures of keloid fibroblasts. Br J Plast Surg. 2003;56(8):804-809.

22. Trisliana Perdanasari A, Lazzeri D, Su W, et al. Recent developments in the use of intralesional injections keloid treatment. Arch Plast Surg. 2014;41(6):620-629.

23. Roques $\mathrm{C}$, Tèot $\mathrm{L}$. The use of corticosteroids to treat keloids: a review. Int J Low Extrem Wounds. 2008;7(3):137-145.

24. Leventhal D, Furr M, Reiter D. Treatment of keloids and hypertrophic scars: a meta-analysis and review of the literature. Arch Facial Plast Surg. 2006;8(6):362-368.

25. Carroll LA, Hanasono MM, Mikulec AA, Kita M, Koch RJ. Triamcinolone stimulates bFGF production and inhibits TGF-beta1 production by human dermal fibroblasts. Dermatol Surg. 2002;28(8):704-709.

26. Muneuchi G, Suzuki S, Onodera M, Ito O, Hata Y, Igawa HH. Longterm outcome of intralesional injection of triamcinolone acetonide for the treatment of keloid scars in Asian patients. Scand J Plast Reconstr Surg Hand Surg. 2006;40(2):111-116.

27. Rahban S, Garner W. Fibroproliferative scars. Clin Plast Surg. 2003;30(1):77-89.

28. Darzi MA, Chowdri NA, Kaul SK, Khan M. Evaluation of various methods of treating keloids and hypertrophic scars: a 10-year follow-up study. Br J Plast Surg. 1992;45:374-379.

29. Acosta S, Ureta E, Yanez R, Oliva N, Searle S, Guerra C. Effectiveness of intralesional triamcinolone in the treatment of keloids in children. Pediatr Dermatol. 2016;33(1):75-79.

30. Finken MJ, Mul D. Cushing's syndrome and adrenal insufficiency after intradermal triamcinolone acetonide for keloid scars. Eur J Pediatr. 2010;169(9):1147-1149.

31. Kumar S, Singh RJ, Reed AM, Lteif AN. Cushing's syndrome after intraarticular and intradermal administration of triamcinolone acetonide in three pediatric patients. Pediatrics. 2004;113(6):1820-1824.

32. Liu MF, Yencha M. Cushing's syndrome secondary to intralesional steroid injections of multiple keloid scars. Otolaryngol Head Neck Surg. 2006;135(6):960-961.

33. Teelucksingh S, Balkaran B, Ganeshmoorthi A, Arthur P. Prolonged childhood Cushing's syndrome secondary to intralesional triamcinolone acetonide. Ann Trop Paediatr. 2002;22(1):89-91.

34. Epstein E. Triamcinolone and keloids. West JMed. 1980;133(3):257-258.

35. Vo A, Doumit M, Rockwell G. The biomechanics and optimization of the needle-syringe system for injecting triamcinolone acetonide into keloids. J Med Eng. 2016;2016:8 (5162394).

36. Doong H, Dissanayake S, Gowrishankar TR, LaBarbera MC, Lee RC. The 1996 Lindberg award. Calcium antagonists alter cell shape and induce procollagenase synthesis in keloid and normal human dermal fibroblasts. J Burn Care Rehabil. 1996;17(6 pt 1):497-514.

37. Boggio RF, Freitas VM, Cassiola FM, Urabayashi M, Machado-Santelli GM. Effect of a calcium-channel blocker (verapamil) on the morphology, cytoskeleton and collagenase activity of human skin fibroblasts. Burns. 2011;37(4):616-625.

38. Ahuja RB, Chatterjee P. Comparative efficacy of intralesional verapamil hydrochloride and triamcinolone acetonide in hypertrophic scars and keloids. Burns. 2014;40(4):583-588. 
39. Danielsen PL, Rea SM, Wood FM, et al. Verapamil is less effective than triamcinolone for prevention of keloid scar recurrence after excision in a randomized controlled trial. Acta Derm Venereol. 2016;96(6):774-778.

40. Kant SB, van den Kerckhove E, Colla C, Tuinder S, van der Hulst RRWJ, Piatkowski de Grzymala AA. A new treatment of hypertrophic and keloid scars with combined triamcinolone and verapamil: a retrospective study. Eur J Plast Surg. 2018;41(1):69-80.

41. Ghoshal K, Jacob ST. An alternative molecular mechanism of action of 5-fluorouracil, a potent anti-cancer drug. Biochem Pharmacol. 1997;53(11):1569-1575.

42. Blumenkranz MS, Claflin A, Hajek AS. Selection of the therapeutic agents for intraocular proliferative disease: cell culture evaluation. Arch Ophthalmol. 1984;102(4):598-604.

43. Wendling J, Marchand A, Mauviel A, Verrecchia F. 5-Fluorouracil blocks transforming growth factor-beta-induced alpha 2 type I collagen gene (COL1A2) expression in human fibroblasts via c-Jun NH2-terminal kinase/activator protein-1 activation. Mol Pharmacol. 2003;64(3):707-713

44. Saha AK, Mukhopadhyay M. A comparative clinical study on role of 5 -flurouracil versus triamcinolone in the treatment of keloids. Indian J Surg. 2012;74(4):326-329.

45. Sadeghinia A, Sadeghinia S. Comparison of the efficacy of intralesional triamcinolone acetonide and 5fluorouracil tattooing for the treatment of keloids. Dermatol Surg. 2012;38(1):104-109.

46. Fitzpatrick RE. Treatment of inflamed hypertrophic scars using intralesional 5-FU. Dermatol Surg. 1999;25(3):224-232.

47. Khan MA, Bashir MM, Khan FA. Intralesional triamcinolone alone and in combination with 5-fluorouracil for the treatment of keloid and hypertrophic scars. J Pak Med Assoc. 2014;64(9):1003-1007.

48. Davison SP, Dayan JH, Clemens MW, Sonni S, Wang A, Crane A. Efficacy of intralesional 5-fluorouracil and triamcinolone in the treatment of keloids. Aesthet Surg J. 2009;29(1):40-46.

49. Gupta S, Sharma VK. Standard guidelines of care: keloids and hypertrophic scars. Indian J Dermatol Venereol Leprol. 2011;77(1): 94-100.

50. Nanda S, Reddy BS. Intralesional 5-fluorouracil as a treatment modality of keloids. Dermatol Surg. 2004;30(1):54-56; discussion 56-57.

51. Apikian M, Goodman G. Intralesional 5-fluorouracil in the treatment of keloid scars. Australas J Dermatol. 2004;45(2):140-143.

52. Mamalis AD, Lev-Tov H, Nguyen DH, Jagdeo JR. Laser and lightbased treatment of Keloids - a review. J Eur Acad Dermatol Venereol. 2014;28(6):689-699.

53. Bass LS, Moazami N, Pocsidio J, Oz MC, LoGerfo P, Treat MR. Changes in type I collagen following laser welding. Lasers Surg Med. 1992;12(5):500-505.

54. Schober R, Urlich F, Sander T, Durselen H, Hessel S. Laser induced alteration of collagen substructure allows microsurgical tissue welding. Science. 1986;232(4756):1421-1422.

55. Dierickx C, Goldmann MP, Fitzpatrick RE. Laser treatment of erythematous/hypertrophic and pigmented scars in 26 patients. Plast Reconstr Surg. 1995;95(1):84-90; discussion 91-92.

56. Nouri K, Vidulich K, Rivas MP. Lasers for scars: a review. J Cosmet Dermatol. 2006;5(1):14-22.

57. Driscoll B. Treating keloids with carbon dioxide lasers. Arch Otolaryngol Head Neck Surg. 2001;127(9):1145.

58. Stern JC, Lucente FE. Carbon dioxide laser excision of ear lobule keloid. Arch Otolaryngol Head Neck Surg. 1989;115(9):1107-1111.

59. Apfelberg DB, Maser MR, White DN, Lash H. Failure of carbon dioxide laser excision of keloids. Lasers Surg Med. 1989;9(4):382-388.

60. Norris JE. The effect of carbon dioxide laser surgery on the recurrence of keloids. Plast Reconstr Surg. 1991;87(1):44-49; discussion 50-53.

61. Verma KK, Garg T, Raj T. Carbon dioxide laser for the treatment of keloids. Indian J Dermatol. 2002;47(2):91-93.

62. Kumar K, Kapoor BS, Rai P, Shukla HS. In situ irradiation of keloid scars with Nd:YAG laser. J Wound Care. 2000;9(5):213-215.

63. Rossi A, Lu R, Frey MK, Kubota T, Smith LA, Perez M. The use of the 300 microsecond $1064 \mathrm{~nm} \mathrm{Nd:YAG} \mathrm{laser} \mathrm{in} \mathrm{the} \mathrm{treatment} \mathrm{of} \mathrm{keloids.}$ J Drugs Dermatol. 2013;12(11):1256-1262.
64. Kassab AN, E1 Kharbotly A. Management of ear lobule keloids using 980-nm diode laser. Eur Arch Otorhinolaryngol. 2012;269(2):419-423.

65. Singhal M, Del Río-Sancho S, Sonaje K, Kalia YN. Fractional laser ablation for the cutaneous delivery of triamcinolone acetonide from cryomilled polymeric microparticles: creating intraepidermal drug depots. Mol Pharm. 2016;13(2):500-511.

66. Perkins K, Davey RB, Walis KA. Silicone gel: a new treatment for burns and contractures. Burns. 1982;9:406-410.

67. Gold MH. A controlled clinical trial of topical silicone gel sheeting in the treatment of hypertrophic scars and keloids. J Am Acad Dermatol. 1994;30(3):506-507.

68. Wood LC, Elias PM, Sequeira-Martin SM, Carl G, Feingold KR. Occlusion lowers cytokine mRNA levels in essential fatty acid-deficient and normal mouse epidermis, but not after acute barrier disruption. J Invest Dermatol. 1994;103(6):834-838.

69. Duncan MR, Beman B. Stimulation of connective tissue related biosynthetic functions of cultured human adult dermal fibroblasts by recombinant human interleukin 6. J Invest Dermatol. 1991;97(4):686-692.

70. Fulton JE Jr. Silicone gel sheeting for the prevention and management of evolving hypertrophic and keloid scars. Dermatol Surg. 1995;21(11):947-951.

71. Katz BE. Silicone gel sheeting in scar therapy. Cutis. 1995;56(1):65-67.

72. Tan E, Chua S, Lim J. Topical silicone gel sheet versus intralesional injections of triamcinolone acetonide in the treatment of keloids - a patient-controlled comparative clinical trial. J Dermatol Treat. 1999;10(4):251-254.

73. Sproat JE, Dalcin A, Weitauer N, Roberts RS. Hypertrophic sternal scars: silicone gel sheet versus Kenalog injection treatment. Plast Reconstr Surg. 1992;90(6):988-992.

74. Kelemen O, Kollár L. Current methods of treatment and prevention of pathologic scars. Magy Seb. 2007;60(2):63-70.

75. Yamawaki S, Naitoh M, Ishiko T, Muneuchi G, Suzuki S. Keloids can be forced into remission with surgical excision and radiation, followed by adjuvant therapy. Ann Plast Surg. 2011;67(4):402-406.

76. Kuo YR, Wu WS, Jeng SF, et al. Activation of ERK and p38 kinase mediated keloid fibroblast apoptosis after flashlamp pulsed-dye laser treatment. Lasers Surg Med. 2005;36(1):31-37.

77. Bodokh I, Brun P. Treatment of keloid with intralesional bleomycin (French). Ann Dermatol Venereol. 1996;123(12):791-794.

78. Payapvipapong K, Niumpradit N, Piriyanand C, Buranaphalin S, Nakakes A. The treatment of keloids and hypertrophic scars with intralesional bleomycin in skin of color. J Cosmet Dermatol. 2015;14(1):83-90.

79. Espana A, Solano T, Quintanilla E. Bleomycin in the treatment of keloids and hypertrophic scars by multiple needle punctures. Dermatol Surg. 2001;27(1):23-27.

80. Farahnaz FN, Jamshid N. Bleomycin tattooing as a promising therapeutic modality in large keloids and hypertrophic scars. Dermatol Surg. 2006;32(8):1023-1029; discussion 1029-1030.

81. Slemp AE, Kirschner RE. Keloids and scars: a review of keloids and scars, their pathogenesis, risk factors, and management. Curr Opin Pediatr. 2006;18(4):396-402.

82. Hackert I, Aschoff R, Sebastian G. The treatment of keloids. Hautarzt. 2003;54(10):1003-1015.

83. Savion Y, Sela M, Sharon-Buller A. Pressure earring as an adjunct to surgical removal of earlobe keloids. Dermatol Surg. 2009;35(3):490-492.

84. AkozT, Gideroglu K, Akan M. Combination of different techniques for the treatment of earlobe keloids. Aesthetic Plast Surg. 2002;26(3):184-188.

85. Chrisostomidis C, Konofaos P, Chrisostomidis G, et al. Management of external ear keloids using form-pressure therapy. Clin Exp Dermatol. 2008;33(3):273-275.

86. Niessen FB, Spauwen PH, Schalkwijk J, Kon M. On the nature of hypertrophic scars and keloids: a review. Plast Reconstr Surg. 1999;104(5):1435-1458.

87. Carvalhaes SM, PetroianuA, Ferreira MA, de Barros VM, Lopes RV. Assessment of the treatment of earlobe keloids with triamcinolone injections, surgical resection, and local pressure. Rev Col Bras Cir. 2015;42(1):9-13.

88. Bran GM, Brom J, Hörmann K, Stuck BA. Auricular keloids: combined therapy with a new pressure device. Arch Facial Plast Surg. 2012;14(1):20-26. 


\section{Publish your work in this journal}

Clinical, Cosmetic and Investigational Dermatology is an international, peer-reviewed, open access, online journal that focuses on the latest clinical and experimental research in all aspects of skin disease and cosmetic interventions. This journal is included on PubMed. The manuscript management system is completely online

Submit your manuscript here: https://www.dovepress.com/clinical-cosmetic-and-investigational-dermatology-journal

and includes a very quick and fair peer-review system, which is all easy to use. Visit http://www.dovepress.com/testimonials.php to read real quotes from published authors 